\title{
Assessing the Effectiveness of Online Human Resources Control in Improving Employees' Performance, During the Pandemic COVID 19, in
}

\section{Lebanon}

\author{
Dana Hankir \\ Lebanon \\ E-mail: hankirdana1@gmail.com
}

Received: Feb. 11, 2021 Accepted: Mar. 12, 2021 Online published: Mar. 25, 2021

doi:10.5296/jpag.v11i1.18456 URL: https://doi.org/10.5296/jpag.v11i1.18456

\begin{abstract}
With the global pandemic of COVID 19 taking place, business organizations had to make their employees work from home. Accordingly, human resources departments had to also apply their functions from home. One of the essential functions of HRM is controlling the performance of employees. When employees had to work from home, HR managers had to apply online control over their employees. The purpose of this research was to identify how HR managers applied online control on their employees and how does online control affect employees' performance. To conduct the study, online control was assessed, and employees' performance was measured through employee's productivity, effectiveness, and efficiency. First of all, a theoretical background has been composed to clearly assess the relation between control and employees' performance. Previous literature on organizational control provided the secondary data. To collect primary data, a quantitative research was applied on employees within organizations in Lebanon. Accordingly, a questionnaire assessing the application of online control and employee's performance was designed and distributed online over 250 employees who worked from home. The responses of the respondents were entered into SPSS and analyzed accordingly. The study tested and approved the correlation between online control and each of employees' productivity, effectiveness, and efficiency. However, correlation between online control and employee's productivity was strong, yet correlations between online control and each of employee's effectiveness and efficiency were weak.
\end{abstract}

Keywords: online control, work from home, performance, productivity, effectiveness, efficiency 


\section{Introduction}

\subsection{HR Online Control During the Global Pandemic COVID 19}

Human resources management is the process of properly administrating the employees, their performance, and everything related to them within any business enterprise. Human resources management (HRM) is implemented through five main functions that include recruitment, training and development, compensation, evaluation and appraisal, control and supervision, and finally employees' relations coordination (Gilbert et al., 2011).

With the existence of the global pandemic worldwide, business organizations needed to find alternatives to keep their employees operating without exposing them to any sort of danger (Chang et al., 2020). By that, the most suitable alternative was making employees work from home. This function became common across organizations and enterprises worldwide. With employees working at a distance and from homes, all operations within all organizations have changed and needed to adapt to the new mode of operation (Chang et al., 2020).

As stated earlier, HRM is the process of managing employees, this means that HR managers now need to manage employees, their performance, and everything related to them at a distance. One function of HRM that greatly depends on the physical presence of the employees is control and supervision. HR managers need to control the working hours of the employees, and evaluate their performance, according to which they set their compensation. That is why control at a distance became a difficult function to apply during the pandemic.

To cope with this problem, HR managers had to find online control policies, and had to create ways to supervise the performance of the employees (Zafar et al, 2021). This research would highlight on the effectiveness of the strategies that have been implemented, and the necessity to find the ways that can make online control more effective in improving employees' performance.

Online control is considered to be a new concept in HRM, such that this function, as it is being applied online, is not much researched. Hence there are no sufficient studies that investigated the application of online control, and how can this mode of operations become effective to boost employees' productivity, effectiveness, and efficiency. Ample literature emphasize the importance of the direct contact between the supervisor and employees in the context of effective supervision, evaluation and control. Therefore, this research will fill the gap in addressing the application of online control and its impact on employees' performance within business organizations in Lebanon.

\subsection{Importance of Online Control in HRM}

Online control is a new HRM concept. This concept has not been well investigated and its effectiveness is still doubted. That is why studying this new concept is crucial to develop HRM. With the pandemic taking place and all employees are operating from home, business managers need to know how to well control and supervise their employees. The study thus seeks to identify if online control the way it is now is improving employees' productivity, 
effectiveness, and efficiency or not. The problem is definitely an added value to HRM theories and highlights the need to make online control more effective in the context of performance. Therefore, this study is important because it implies at the effectiveness of the current online control policies applied in improving employees' performance.

\subsection{Theoretical and Empirical Review}

\subsubsection{Control as a HRM Function}

Different research has been done to define control as an HRM function. Flamholtz, Das, \& Tsui, (1985) and Snell (1992) defined control as the process of supervising the performance of the employees in implementing their tasks and duties to make sure that the organizational goals are met. Control also includes monitoring the performance of employees to reward or punish the ones that do not meet the obligations of the organization. Kirsch (1996) and Verburg et al. (2018) stated that control has three main purposes, first of all to secure the attainment of the business goals and outcomes, second, control aims to provide employees with performance standards, and thirdly it aims to apply discipline at the work place (Sitkin et al., 2010).

However, theory and research put emphasis on the importance of the direct contact between supervisor and employee in the workplace, for a fruitful face to face interaction, supervision, evaluation, and hence effective control. The American social psychologist Rensis Likert, offered many books related to management, conflict, and applications of behavioral research, and had important contributions in enhancing organizations' behaviors in managing their subordinates effectively. Likert (1961) discussed how control and supervision should be done in person between employers and employees. The process of control is related to the direct monitoring of the subordinates' performance during their working hours in the workplace. Managers need to closely know how employees are spending their time during working hours, what kind of tasks are they doing, how much time is the task taking, how they are behaving and abiding the rules and procedures... Therefore the presence of both supervisors and employees at the same physical location is vital and essential for effective supervision, evaluation, and control. The interviewee, Prof. Dr. Moussa Khalil, a certified international expert in HRM\&D, announced that "Control has to achieve its strategic objective in evaluating employees' performance on their jobs. In order to achieve organizational goals in an efficient and effective manner, control has to be directly conducted through direct interactions among supervisors and employees. Such methodology, triggers human and social feelings of employees and turns them into effective, efficient, and competent employees. Online control eliminates the human and social feature of individuals. Performance is not based on technology efficiency as much as it is based on humans' abilities to deal with the complexities of their tasks in the workplace. Online control is a technique of control, yet it is not an effective instrument in evaluating performance. Reporting is the best method to evaluate employee performance at distance, even though this might not fully reflect the respective efforts as there might be some irregularities in behavior and unfairness in appraising may rise".

\subsubsection{Employees’ Performance}


Employees' performance corresponds to the way, accuracy, and time employees apply and conduct their operations, tasks, and duties. Business organizations seek to achieve these goals that is why they divide the tasks and responsibilities among their employees within different units. They set operational goals for each employee, such that, when employees achieve their operational goals, the organizational goals will be automatically achieved as well.

Employee performance is related whether employees are able to achieve their goals or not, it has to do with the costs expended to reach these goals, and the quantity of work within a specific timeframe.

\subsubsection{Employees' Productivity}

By definition, employees' productivity refers to the quantity of work done within a specific period of time. Business organizations seek to maximize the work that can be done within a specific timeframe without affecting the quality of the work (Verburg et al., 2018). That is why business organizations always seek to make their employees perform maximum quantity of work and apply as many tasks as possible during their working hours. Employee productivity increases when employees are able to perform more tasks in less time (Verburg et al., 2018).

\subsubsection{Employees' Effectiveness}

Ma et al. (2016) considered that employees' effectiveness is a concept that is related to doing the work properly and achieve the needed targets and goals. Work effectiveness is the process of properly doing the job or tasks with no errors or mistakes and making sure that the goals set by the organization are met (Ma et al., 2016).

\subsubsection{Employees' Efficiency}

Employees' efficiency is the process related to the input of resources employees need to provide the output of results (Wang et al., 2020). Organizations thus tend to minimize the input of resources and maximize the output of results. With that being said, business organizations tend to increase their employees' efficiency. They want them to use the minimal resources and provide the maximum output (Wang et al., 2020)

\subsubsection{Application of Control and Its Impact on Employees' Performance}

As stated earlier, control aims to monitor the performance of employees in order to first make sure that operational and organizational goals are attained, to provide employees with performance standards, and finally to sustain discipline at work. Control is usually applied in different modes of operations (Ma et al., 2021). First of all, since the first moment employees step into their workplace they need to prove their attendance, that is why many business organizations utilize technology to record the entrance and exit of employees from work place. This first of all allows HR managers to control the working hours of employees. Employees are thus paid upon their working hours, this also allows the HR manager to identify who is arriving late and who is leaving early. This will also allow the HR manager to punish employees who do not apply the rules, and this secures discipline at work (Ma et al., 2021). 
Cai (2020) added to that and indicated that HR managers and supervisors set task deadline to their employees to make sure that they deliver the task within the needed time frame. Setting deadline to employees and monitoring their work behavior would secure that employees are fully focused, and will effectively deliver their tasks on time. HR managers also apply work appraisals to make sure that employees are meeting the deadlines, delivering quality work, and achieving their operational objectives.

Huselid (1995) confirms a relation between HR managers control and employees performance. He indicates that control would make employees dedicated to their work. This will push them to achieve their goals and deliver the quantity and quality their managers expect. Huselid (1995) approved that organization control improves employees' performance within business organizations, and that controlled employees are more likely to deliver quantity and quality work more than non-controlled employees. He stated that controlled employees dedicate their time and effort, this automatically increases productivity, effectiveness, and efficiency. This increases productivity because it makes employees work more in less time, it increases effectiveness because it allows employees to achieve their operational goals, and it increases efficiency because it reduces costs (time) and produce more output (Huselid, 1995).

Hauff et al. (2014) highlighted in his study that organizational control would direct employees on the goals they need to do, it allows the correction of errors in case any happens, rewards, and punishes employees when they fail to attain their goals. Hauff et al. (2014) also proved that controlled employees perceive their organizational goals as their own goals, and this would increase their work in terms of quality and quantity, leading to increase in productivity, effectiveness, and efficiency.

\subsubsection{Implementation of Online Control}

With the pandemic of COVID-19 taking place, employees had to work from home, and HR managers had to apply their functions and control their employees also from home. First thing that was impossible to be done is to follow up on all employees physically (Flinchbaugh et al., 2020). Many HR managers had to create an online platform where employees had to record their entry and exist time. This allowed HR manages to identify when did their employees started working. Huo et al. (2020) indicated that HR managers connected the work system to the employees private computers, and they controlled how many hours have been the system opened or accessed. Yet, HR managers were not able to supervise the physical behavior of the employees during their work from home, nor they were able to control any kind of distractions they might have (Huo et al., 2020). HR managers were not able to impose any power on employees and could not monitor their actions and functions. Some HR managers set deadline and time frames to their employees to make sure that they are working all the time, and employees were obliged to send whatever has been done from the task by the deadline set (Huo et al., 2020). This allowed the HR managers to identify if employees are really working from home or not. Another common practice by HR managers was requesting a daily report from employees. Employees in many organizations had to prepare a daily report that starts with the time they record their entrance till their exit. 


\section{Macrothink}

The report includes detailed filling for the tasks that have been done and the time that has been consumed (Huo et al., 2020). So that, every day, employees had to fill how they executed their daily schedule to their managers. This also made employees committed and made sure that organizations operations are being done to reach the organizational goals. Therefore, one can conclude that online control is the process of controlling employees' performance with organizations through online tools (Huo et al, 2020).

\subsection{Research Conceptual Model}

Based on related literature, especially the above theoretical and empirical review, the following model can be extracted to be investigated:

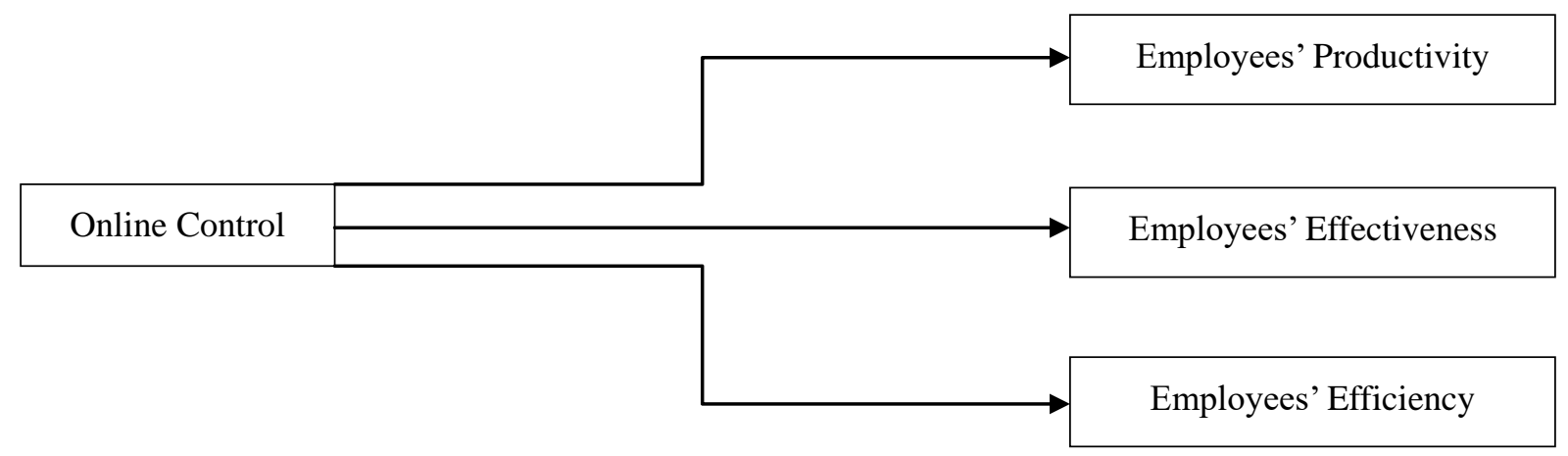

Figure 1. Research Conceptual Model

\subsection{Research Hypotheses and Correspondence to Research Design}

The theoretical and empirical background illustrated and presented the impact of control on employees' performance. It declared that control is one function of HRM and would increase employees' productivity, effectiveness, and efficiency.

Due to the pandemic, control is being done online and at distance. Therefore, it is essential to know if control at a distance has the same impact on employees' performance when it comes to their productivity, effectiveness, and efficiency.

Therefore, the research will investigate the correlation between online control from one side, and each of employees' productivity, effectiveness, and efficiency from another side. Therefore, the hypothesis of the study will be a correlation exists between online control and employee's performance, and the secondary hypotheses will be a correlation exists between online control and each of the three dimensions of employee's performance.

The research will clearly indicate how online control impacted each of employees' productivity, effectiveness, and efficiency, and this will imply about the effectiveness of online control on improving employees' performance.

Based on what has been presented the following hypothesis will be investigated: 


\section{Macrothink}

Journal of Public Administration and Governance

ISSN 2161-7104

2021, Vol. 11, No. 1

$\mathrm{H}_{0}$ : There is no correlation between implementing online control and employees' performance

$\mathrm{H}_{1:}$ There is a positive correlation between implementing online control and employees' performance.

Employees' performance will be assessed by assessing employees' productivity, effectiveness, and efficiency. Therefore, the secondary hypotheses of the research will be the following:

$\mathrm{H}_{0.1}$. There is no correlation between implementing online control and employees' productivity

$\mathrm{H}_{0.2}$. There is no correlation between implementing online control and employees' effectiveness

$\mathrm{H}_{0.3}$. There is no correlation between implementing online control and employees' efficiency

$\mathrm{H}_{1.1}$. There is a positive correlation between implementing online control and employees' productivity

$\mathrm{H}_{1.2}$. There is a positive correlation between implementing online control and employees' effectiveness

$\mathrm{H}_{1.3}$. There is a positive correlation between implementing online control and employees' efficiency.

The hypotheses of the study either approve the correlation between implementing online control and each of the dimensions of employees' performance or not.

The study will accordingly provide theoretical background on how effective is online control, and will also provide recommendations to make online control effective in practice.

\section{Method}

The study aims to assess the impact of online control on each of employees' productivity, effectiveness, and efficiency. Therefore, the independent variable in the research was exposure to online control and the dependent variable was employee's performance including employees' productivity, effectiveness, and efficiency. Consequently, quantitative approach was adopted through a questionnaire. This approach was believed ideal because it extracted both statistical and arithmetic metrics to describe the relationship between dependent and independent variables.

In order to design the questionnaire, the findings from the theoretical and empirical review were used. This review presented the objectives of control, it also presented the impact of control on employees' performance and then presented how online control is applied. These findings were re-structured and re-phrased into statements composing the questionnaire.

The study aims to assess the performance of employees who have been operating at a distance and online control was applied on them. Therefore, the participants of the study would be employees who have been working from home and exposed to online control. 


\section{Macrothink}

Journal of Public Administration and Governance

ISSN 2161-7104

2021, Vol. 11, No. 1

Therefore, all employees working in Lebanese business organizations from home and have been exposed to online control are liable and eligible to participate in the study.

The population in Lebanon is very large. According to a report issued in September 2020, by the International Labour Organization (ILO), in collaboration with The Daily Star Lebanon, more than 5000 employees were forced to work from home. According to Creswell (2007) when the population size is less than 10000 respondents, the best sample size is $5 \%$ of the population. Accordingly with a population of 5000 employees, the sample size was 250 respondents. Therefore, 250 respondents of employees who had to work from home were selected.

Random sampling has been applied in this study. With the pandemic of COVID 19 taking place in Lebanon, all enterprises who were not exempted from the lockdown were forced to operate from home. This means that the sample of the study is large and includes more than 5000 employees working in different sectors (ILO \& The Daily Star, 2020). Therefore random sampling has been applied and employees were selected accordingly. Also, considering the pandemic and work from home, the questionnaire was uploaded on google forms and was distributed to the respondents through emails, and WhatsApp. Respondents were asked to identify their degree of agreement on the questionnaire statements using a five point's Likert scale.

Finally responses of the employees were entered into SPSS, where reliability and validity were assessed first, then data analysis was done: Descriptive statistics, mean test, Pearson correlation, and regression.

\section{Results}

This section presents the data that were obtained from the questionnaire. It illustrates the findings of the questionnaire and accordingly provide equations and formulas to come up with conclusion.

\subsection{Sample Description}

The sample was composed of 250 respondents operating in different kinds of businesses. The sample was highly diversified. $51 \%$ of the respondents were males and $49 \%$ were females. $32 \%$ of the respondents were employees whose age ranges between 41 and 50 years, and 23\% of the respondents were employees whose age ranges between 21 and 30 years. Such that, $44 \%$ of them hold senior positions, and $32 \%$ of them hold managerial positions. Finally, $32 \%$ of the respondents work within management and administrative departments, and $23 \%$ of them work within the marketing department. Other departments included accounting $(16.4 \%)$, IT and programming (16\%), and logistics (11.6\%).

\subsection{Other Statistics and Data Analysis}

\subsubsection{Reliability and Validity}

Reliability and validity test were the tests conducted first, after data collection, in order to proceed with the analysis. First, Cronbach's alpha was conducted. It scored 0.955 indicating a 
high reliability. Second, factor analysis was done to test validity and group statements. Only one statement was excluded from the set of statements related to employees' effectiveness.

\subsubsection{Mean Test}

In order to assess the responses of the respondents, a mean test was done. The mean test aimed at identifying the average agreement on the statements that have been tested and subjected in the questionnaire. The following table presents the means of each item in the questionnaire:

Table 1. Mean Test

\begin{tabular}{lcc}
\hline & $\mathrm{N}$ & Mean \\
\hline HR manger records our starting and exit time even when operating from home & 250 & 4.164 \\
HR manager requests a detailed report of the tasks and duties performed & & \\
within the working hours & 250 & 3.648 \\
HR manager sets deadlines for all tasks and operations I should be doing per & & \\
day & 250 & 4.164 \\
HR manager or my supervisor expect a specific quality from me when I work & & \\
from home & 250 & 4.32 \\
I respect the rule and regulations of my business & 250 & 4.484 \\
I apply all rules and regulations even if I am working from home & 250 & 3.976 \\
We still get rewards and penalties when we work from home & 250 & 4.596 \\
I am able to perform more tasks when I work at home than when I work from & & \\
office & 250 & 3.252 \\
Within a specific period of time I am always able to complete many duties & 250 & 3.372 \\
I am able to follow on more tasks from home & 250 & 3.528 \\
I always deliver the tasks I do at home before their deadlines & 250 \\
I work better from home than office & 250 \\
The quality of work I do at home is better from that I do in the office & 250 & 3.888 \\
My manager is satisfied with the work I do at home & 250 & 4.392 \\
I do less mistakes when I work from home & 250 & 4.224 \\
I always meet my deadlines when I work from home & 250 & 4.22 \\
I need less time to finish tasks and operations when I work from home & 250 & 4.392 \\
I need less mental input when I work from home & 250 & 4.124 \\
\hline
\end{tabular}

When respondents were asked if the HR manager records our starting and exit time even when operating from home the mean scored 4.164. This means that the respondents agreed with that

When respondents were asked if the HR manager requests a detailed report of the tasks and duties performed within the working hours the mean scored 3.648. This means that the respondents neither agreed nor disagreed with that

When respondents were asked if the HR manager sets deadlines for all tasks and operations I should be doing per day the mean scored 4.164. This means that the respondents agreed with that 
When respondents were asked if the HR manager or my supervisor expect a specific quality from me when I work from home the mean scored 4.32. This means that the respondents agreed with that

When respondents were asked if they respect the rule and regulations of the business the mean scored 4.484. This means that the respondents agreed with that

When respondents were asked if they apply all rules and regulations even if they are working from home the mean scored 3.976. This means that the respondents agreed with that

When respondents were asked if they still get rewards and penalties when they work from home the mean scored 4.596. This means that the respondents agreed with that

When respondents were asked if they are able to perform more tasks when they work at home than when I work from office the mean scored 3.252. This means that the respondents neither agreed nor disagreed with that

When respondents were asked within a specific period of time they are always able to complete many duties the mean scored 3.372. This means that the respondents neither agreed nor disagreed with that

When respondents were asked if they are able to follow on more tasks from home the mean scored 3.528. This means that the respondents neither agreed nor disagreed with that

When respondents were asked if they always deliver the tasks they do at home before their deadlines the mean scored 3.888. This means that the respondents neither agreed nor disagreed with that

When respondents were asked if they work better from home than office the mean scored 4.392. This means that the respondents agreed with that

When respondents were asked if the quality of work I do at home is better from that I do in the office the mean scored 4.224. This means that the respondents agreed with that

When respondents were asked if the manager is satisfied with the work they do at home the mean scored 4.22. This means that the respondents agreed with that

When respondents were asked if they do less mistakes when they work from home the mean scored 4.392. This means that the respondents agreed with that

When respondents were asked if they always meet my deadlines when they work from home the mean scored 4.436. This means that the respondents agreed with that.

When respondents were asked if they need less time to finish tasks and operations when they work from home the mean scored 4.124. This means that the respondents agreed with that

When respondents were asked if they need less mental input when they work from home, the mean scored 3.952. This means that the respondents agreed with that

\subsubsection{Correlation Test}




\section{Ml Macrothink}

The questionnaire assessed the variables: online control, and employees' productivity, effectiveness, and efficiency. Then a correlation test was done between online control as independent variable from one side with each of employees' productivity, employees' effectiveness, and employees' efficiency as dependent variables from the other side. It is important to note that a correlation is only approved when significance scores less than 0.05 . The results were as the following:

Table 2. Control Test

\begin{tabular}{llrrr}
\hline & & $\begin{array}{c}\text { Employees } \\
\text { Productivity }\end{array}$ & $\begin{array}{c}\text { Employees } \\
\text { Effectiveness }\end{array}$ & $\begin{array}{c}\text { Employees } \\
\text { Efficiency }\end{array}$ \\
\hline Online Control & Pearson Correlation & $.902^{* *}$ & $.200^{* *}$ & $.212^{* *}$ \\
& Sig. (2-tailed) & .000 & .001 & .001 \\
& $\mathrm{~N}$ & 250 & 250 & 250 \\
\hline
\end{tabular}

Significance between online control and employees' productivity scored a value of 0.000 which is less than 0.05 , this means that correlation between online control and employees' productivity is approved $100 \%$.

Significance between online control and employees' effectiveness scored a value of 0.001 which is less than 0.05 , this means that correlation between online control and employees' productivity is approved $99.9 \%$.

Significance between online control and employees' efficiency scored a value of 0.001 which is less than 0.05, this means that correlation between online control and employees' productivity is approved $99.9 \%$.

Furthermore, all correlations had positive values.

\subsubsection{Regression Analysis}

To further approve the correlation and identify the strength and the degree of dependency, regression tests were done. In a regression test, $\mathrm{R}$ signifies the strength of the correlation and adjusted R square signifies the dependency correlation.

In the first regression test, the independent variable was online control and the dependent variable was employees' productivity.

Table 3. Regression Test 1

\begin{tabular}{lcccc}
\hline \multicolumn{4}{c}{ Model Summary } \\
\hline Model & R & R Square & $\begin{array}{c}\text { Adjusted R } \\
\text { Square }\end{array}$ & $\begin{array}{c}\text { Std. Error of } \\
\text { the Estimate }\end{array}$ \\
\hline 1 & $.902^{\mathrm{a}}$ & .814 & .813 & .43225552 \\
\hline a. Predictors: (Constant), Online Control
\end{tabular}

$\mathrm{R}$ scored 0.902 , this means that the strength of the correlation between online control and employees' productivity is $90.2 \%$. 


\section{Macrothink}

Journal of Public Administration and Governance

ISSN 2161-7104

2021, Vol. 11, No. 1

Adjusted R square scored 0.813 , this means that employees productivity depends on online control by $81.3 \%$.

In the second regression test, the independent variable was online control and the dependent variable was employees' effectiveness.

Table 4. Regression Test 2

\begin{tabular}{llrrr}
\hline \multicolumn{5}{c}{ Model Summary } \\
\hline Model & \multicolumn{1}{c}{ R } & R Square & $\begin{array}{c}\text { Adjusted R } \\
\text { Square }\end{array}$ & $\begin{array}{r}\text { Std. Error of } \\
\text { the Estimate }\end{array}$ \\
\cline { 2 - 5 } 1 & $.200^{\mathrm{a}}$ & .040 & .036 & .98179626 \\
\hline
\end{tabular}

a. Predictors: (Constant), Online Control

$\mathrm{R}$ scored 0.200 , this means that the strength of the correlation between online control and employees' effectiveness is $20 \%$.

Adjusted R square scored 0.036 , this means that employees effectiveness depends on online control by $3.6 \%$.

In the third regression test, the independent variable was online control and the dependent variable was employees' efficiency.

Table 5. Regression Test 3

\begin{tabular}{|c|c|c|c|c|}
\hline \multicolumn{5}{|c|}{ Model Summary } \\
\hline Model & $\mathrm{R}$ & R Square & $\begin{array}{l}\text { Adjusted R } \\
\text { Square }\end{array}$ & $\begin{array}{l}\text { Std. Error of } \\
\text { the Estimate }\end{array}$ \\
\hline 1 & $.212^{\mathrm{a}}$ & .045 & .041 & .97930960 \\
\hline
\end{tabular}

a. Predictors: (Constant), Online Control

$\mathrm{R}$ scored 0.212 this means that the strength of the correlation between online control and employees' efficiency is $21.2 \%$.

Adjusted R square scored 0.041 this means that employees' productivity depends on online control by $4.1 \%$.

\section{Discussion and Conclusion}

The findings of the research provided new insights about online control and its impact on employee's performance within organizations. The findings in fact approved what has been originally known about control, yet significance of online control on employee's effectiveness and efficiency varied. The findings of this research confirmed what Huselid (1995) stated about that fact that organizational control increases and improves employees performance. However, Huselid (1995) indicated that organizational control would greatly affect employees work in quality and quantity. The current study revealed that online control has an impact on employee's effectiveness and efficiency, yet the impact is not very much significant as traditional control. Yet Huselid (1995) also indicated that employees' productivity is highly correlated with organizational control. This finding was approved 
significantly. Similarly, Hauff et al. (2014) indicated that traditional organizational control reduces errors in employee's performance, provides better quality, and requires less time. Hauff et al. (2014) also indicated a strong correlation between control and productivity, effectiveness, and efficiency. Apparently, this research approved the three correlations yet significance of the correlation varied. As per the regression test, productivity depends on online control by $81.3 \%$, but each of employee's effectiveness and efficiency depends on online control by only $3.6 \%$ and $4.1 \%$ respectively.

Based on the findings, $\mathrm{H} 0$ was rejected and $\mathrm{H} 1$ was approved:

H1: There is a positive correlation between implementing online control and employees' performance.

Therefore, the approved secondary hypotheses of the research will be the following:

H1.1. There is a positive correlation between implementing online control and employees' productivity

H1.2. There is a positive correlation between implementing online control and employees' effectiveness

H1.3. There is a positive correlation between implementing online control and employees' efficiency.

In conclusion, online control proved to have significant impact on employees' performance. In fact, it proved to have significant impact on employees' productivity, yet it had minimal impact on employees' effectiveness and efficiency.

It is also important to mention that conducting the study had some limitations. First of all, employees will not be objective when evaluating their performance, they might be subjective. Furthermore, conducting the study was limited by online tools due to the global pandemic. Employees reported that they are performing more tasks when they operate from home, yet they are not effective and efficient as they should.

Finally, online control remains a new un-researched concept within human resource management. Such that further research should be done to identify how should online control be done, and what are the factors that would affect the effectiveness of online control.

\section{Acknowledgments}

I would like to thank all friends and respondents who have taken a part in conducting this research in the current difficult times the world is passing through.

\section{References}

Cai, Y. (2020). High-performance work systems in mainland China: a review and research agenda. Asia Pacific Business Review, 26(5), 563-587. https://doi.org/10.1080/13602381.2020.1791490

Chang, H., Son, S. Y., \& Pak, J. (2020). How do leader-member interactions influence the 
HRM-performance relationship? A multiple exchange perspective. Human Performance, 33(4), 282-301. https://doi.org/10.1080/08959285.2020.1746315

Creswell, J. W. (2007). Qualitative inquiry and research design: Choosing among five approaches (2nd ed.). Sage Publications, Inc.

Flamholtz, E. G., Das, T. K., \& Tsui, A. S. (1985). Toward an integrative framework of organizational control. Accounting, organizations and society, 10(1), 35-50. https://doi.org/10.1016/0361-3682(85)90030-3

Flinchbaugh, C., Ishqaidef, G., \& Chadwick, C. (2020). A Shared Human Resources Change Initiative: What Influences (in) Effectiveness?. Journal of Change Management, 20(4), 369-386. https://doi.org/10.1080/14697017.2020.1758748

Gilbert, C., De Winne, S., \& Sels, L. (2011). The influence of line managers and HR department on employees' affective commitment. The International Journal of Human Resource Management, 22(8), 1618-1637. https://doi.org/10.1080/09585192.2011.565646

Hauff, S., Alewell, D., \& Hansen, N. K. (2014). HRM systems between control and commitment: Occurrence, characteristics and effects on HRM outcomes and firm performance. Human resource management journal, 24(4), 424-441. https://doi.org/10.1111/1748-8583.12054

Huo, M. L., Boxall, P., \& Cheung, G. W. (2020). How does line-manager support enhance worker wellbeing? A study in China. The International Journal of Human Resource Management, 31(14), 1825-1843. https://doi.org/10.1080/09585192.2017.1423103

Huselid, M. A. (1995). The impact of human resource management practices on turnover, productivity, and corporate financial performance. Academy of management journal, 38(3), 635-672. https://doi.org/10.2307/256741

ILO and The Daily Star Lebanon (2020). Rapid Diagnostic Assessment of Employment Impacts under COVID 19 in Lebanon, available at https://www.ilo.org/emppolicy/pubs/WCMS_754666/lang--en/index.htm

Kirsch, L. J. (1996). The management of complex tasks in organizations: Controlling the systems development process. Organization science, $7(1), \quad 1-21$. https://doi.org/10.1287/orsc.7.1.1

Likert, R. (1961). New patterns of management.

Ma, S., Silva, M. G., Callan, V. J., \& Trigo, V. (2016). Control and commitment HR practices, job satisfaction and turnover intentions: a comparison between local and multinational firms in China. The International Journal of Human Resource Management, 27(9), 974-990. https://doi.org/10.1080/09585192.2015.1052535

Ma, S., Xu, X., Trigo, V., \& Ramalho, N. J. (2021). Managing Doctor-Patient Relationships and Turnover Intention in Chinese Hospitals with Commitment HRM: The Moderating Role of Pragmatism. International Journal of Public Administration, 44(2), 167-176. 


\section{Macrothink}

Journal of Public Administration and Governance

ISSN 2161-7104

2021, Vol. 11, No. 1

https://doi.org/10.1080/01900692.2019.1672725

Sitkin, S. B., Cardinal, L. B., \& Bijlsma-Frankema, K. M. (Eds.). (2010). Organizational control. Cambridge University Press. https://doi.org/10.1017/CBO9780511777899

Snell, S. A. (1992). Control theory in strategic human resource management: The mediating effect of administrative information. Academy of management Journal, 35(2), 292-327. https://doi.org/10.2307/256375

Verburg, R. M., Nienaber, A. M., Searle, R. H., Weibel, A., Den Hartog, D. N., \& Rupp, D. E. (2018). The role of organizational control systems in employees' organizational trust and performance outcomes. Group \& organization management, 43(2), 179-206. https://doi.org/10.1177/1059601117725191

Wang, Y., Kim, S., Rafferty, A., \& Sanders, K. (2020). Employee perceptions of HR practices: A critical review and future directions. The International Journal of Human Resource Management, 31(1), 128-173. https://doi.org/10.1080/09585192.2019.1674360

Zafar, R., Abid, G., Rehmat, M., Ali, M., Hassan, Q., \& Asif, M. F. (2021). So hard to say goodbye: impact of punitive supervision on turnover intention. Total Quality Management \& Business Excellence, 1-23. https://doi.org/10.1080/14783363.2021.1882844

\section{Copyright Disclaimer}

Copyright for this article is retained by the author(s), with first publication rights granted to the journal.

This is an open-access article distributed under the terms and conditions of the Creative Commons Attribution license (http://creativecommons.org/licenses/by/4.0/). 